\title{
Evaluation of an oral telomerase activator for early age-related macular degeneration - a pilot study
}

\author{
This article was published in the following Dove Press journal: \\ Clinical Ophthalmology \\ 28 January 2016 \\ Number of times this article has been viewed
}

\section{Coad Thomas Dow ${ }^{1,2}$ \\ Calvin B Harley ${ }^{3}$}

'McPherson Eye Research Institute, University of Wisconsin-Madison, Madison, WI, USA; ${ }^{2}$ Chippewa Valley Eye Clinic, Eau Claire, Wisconsin, WI, USA; ${ }^{3}$ Independent Telomere Biology Consultant, Murphys, CA, USA
Correspondence: Coad Thomas Dow Chippewa Valley Eye Clinic, 27I5 Damon Street, Eau Claire, Wisconsin, WI, USA $\mathrm{Tel}+\mathrm{I} 715834847 \mid$

Fax +I 7I5 8340373

Email ctdow@me.com
Purpose: Telomere attrition and corresponding cellular senescence of the retinal pigment epithelium contribute to the changes of age-related macular degeneration. Activation of the enzyme telomerase can add telomeric DNA to retinal pigment epithelium chromosomal ends and has been proposed as a treatment for age-related macular degeneration. We report the use of a small molecule, oral telomerase activator (TA)-65 in early macular degeneration. This study, focusing on early macular degeneration, provides a model for the use of TAs in age-related disease.

Method: Thirty-eight (38) patients were randomly assigned to a 1-year, double-blinded, placebo-controlled interventional study with arms for oral TA-65 or placebo. Macular functions via micro-perimetry were the primary measured outcomes.

Results: The macular function in the arm receiving the TA- 65 showed significant improvement relative to the placebo control. The improvement was manifest at 6 months and was maintained at 1 year: macular threshold sensitivity (measured as average $\mathrm{dB}$ [logarithmic decibel scale of light attenuation]) improved $0.97 \mathrm{~dB}$ compared to placebo ( $P$-value 0.02$)$ and percent reduced thresholds lessened 8.2\% compared to the placebo arm ( $P$-value 0.04$)$.

Conclusion: The oral TA significantly improved the macular function of treatment subjects compared to controls. Although this study was a pilot and a larger study is being planned, it is noteworthy in that it is, to our knowledge, the first randomized placebo-controlled study of a TA supplement.

Keywords: drusen, macular degeneration, micro-perimetry, senescence, telomerase activation, telomere

\section{Background}

The retinal pigment epithelium (RPE) plays a pivotal role in vision and in the pathogenesis of age-related macular degeneration (AMD), the leading cause of blindness in the elderly in developed countries. ${ }^{1,2}$ While there is great variety in the manifestation of AMD, it is now classified as "early", "intermediate", and late AMD. Of the late AMD there is atrophic ("dry") and neovascular ("wet") degeneration. ${ }^{3}$ Although there are newer treatments for wet degeneration, dry AMD - accounting for $80 \%-90 \%$ of the disease - still lacks effective therapy.

Seminal work regarding nutritional antioxidants and AMD started in the late 1980s and led to the large Age Related Eye Disease Study (AREDS). The results of the AREDS study showed that supplementation with antioxidants and zinc reduced the risk of progression to advanced AMD by approximately $25 \%$ in those with intermediate AMD or advanced AMD in one eye. Although encouraging, the study showed no benefit of antioxidants and zinc in early AMD. ${ }^{4,5}$ A subsequent study with a reformulation (AREDS2) demonstrated an additional effect, again for those with moderate stage AMD. However, like the original AREDS study, the AREDS2 study showed no benefit (or harm) for individuals with early AMD. ${ }^{6}$ 
Of the multiple functions of the RPE one of the most important is the macrophage capacity to support the maintenance of the retina's photoreceptors. Phagocytosis of spent outer segment membranes (discs) shed by the photoreceptors occurs at the apical surface of RPE. There are approximately 150 million photoreceptors in the human retina. Photoreceptors shed as many as 100 of their outer discs per day. Disc shedding is the process by which photoreceptors in the eye are renewed. ${ }^{7}$ These are continually replaced by the addition of new disks at the base of the stack. For homeostasis, each RPE cell needs to ingest as many as 4,000 outer segment discs per day. ${ }^{8}$

The early stage of AMD is characterized by the presence of drusen, which are yellow deposits between the RPE and Bruch's membrane of the aged retina. How drusen deposits are formed remains controversial. Some believe that drusen may be un-phagocytosed debris that translocates from the apical to sub-RPE region; ${ }^{9}$ while others propose that drusen may be the result of exocytosis of phagocytosed materials undegradable by the RPE. ${ }^{10}$ RPE cells undergo senescence both in culture and in vivo ${ }^{11-13}$ and RPE senescence is accompanied by an increase in beta-galactosidase activity indicative of cellular senescence and lysosomal dysfunction resulting in ineffective phagocytosis. ${ }^{14}$ A better understanding of the senescent phenotype in age-related disease is evolving and it relates to telomere shortening. ${ }^{15,16}$

Telomeres are protective nucleotide repeats (TTAGGG) at the ends of chromosomes and due to the "end replication problem"17 are sequentially shortened with each cell division. Loss of telomeric DNA occurs during cell division because the end of the lagging strand of the chromosome cannot be fully replicated. ${ }^{18}$

Cellular senescence is generally considered to result from critical telomere attrition. ${ }^{16}$ Specifically, results in a recent article show that telomere length is associated with AMD risk $^{19}$ and that telomere attrition plays an important role in a variety of age-related diseases as well as AMD. ${ }^{20,21}$

This loss can be restored by the enzyme telomerase. ${ }^{22,23}$ Telomerase is a reverse transcriptase with an intrinsic RNA template that produces new telomeric DNA; telomere erosion reflects the sum of the telomere loss and telomere restoration by telomerase..$^{23,24}$ In addition to telomere loss during cell division, there are other factors that can shorten telomeres, including oxidative stress. ${ }^{24}$ Oxidative stress is associated with accelerated telomere shortening, and can be accompanied by a rapid entry of cells into senescence. ${ }^{25}$ The central retina is required to respond to an exceptionally high oxidative stress load and that load is further increased with aging. ${ }^{26,27}$
A small molecule compound isolated from the Astragalus membranaceus plant is capable of up-regulating telomerase activity. ${ }^{28}$ This was identified in an empirical screening of traditional Chinese medicinal plant extracts and compounds having reported properties of health maintenance and enhanced immune function. A purified proprietary compound from this plant has been available commercially since 2007 as a nutraceutical product, telomerase activator (TA)-65 (www.tasciences. $\underline{\text { com) }}$, and carries a "generally regarded as safe" designation. The dosage reflects the pharmacokinetics of in vitro testing. ${ }^{29}$

As up-regulation of telomerase, an enzyme that adds tandem repeats of TTAGGG, can "rescue" cells from senescence and result in an improved functioning RPE, telomerase activation has been proposed as treatment for macular degeneration. ${ }^{30,31}$ RPE cells were the first cell type used in transfection studies to demonstrate the ability to immortalize normal cells through telomerase activation, without causing cancer, or cell transformation. ${ }^{32,33}$ TA-65 is a low to moderate TA that enhances the replicative capacity of human RPE cells without apparent toxicity; in this study we propose that a treatment effect is due to an enhanced replicative capacity of the RPE. ${ }^{34}$

Visual function alteration, such as abnormal retinal sensitivity in the central visual field, occurs in early AMD. ${ }^{35}$ Microperimetry, via the macular integrity assessment (MAIA; Centervue, Padova, Italy) instrument, is a sensitive and clinically meaningful tool to assess and monitor macular function in $\mathrm{AMD}$, and is much more sensitive in monitoring change than standard visual acuity measurement. ${ }^{36}$ Micro-perimetry has shown decreased macular sensitivity in areas of drusen and RPE hyperpigmentation despite preserved visual acuity. ${ }^{37}$ Normal visual acuity may be present until the development of later stages of AMD, thus, measured visual acuity is not a reliable functional parameter in the evaluation of these patients. ${ }^{38}$ We tested individuals with early AMD to see if the use of an oral TA could impact the course of their disease, compared to placebo, as measured by micro-perimetry.

\section{Methods}

In this pilot study, 38 subjects with macular drusen (AREDS 2, 3 ) were randomly assigned to parallel, interventional, doubleblinded study arms with oral TA-65 (8 mg purified Astragalus root extract) or placebo twice daily. TA- 65 " is a $>95 \%$ pure single chemical entity isolated from a proprietary extract of the dried root of Astragalus membranaceus" ${ }^{28}$ The placebo capsule contained excipients only. The contents and appearances of placebo capsules and TA-65 were indistinguishable in all aspects: shape, size, weight, and packaging except that one was labeled " $A$ " and the other "B". The participants, investigators, 
coordinators, and analysts of the data from the study were blinded to the identity of the bottles A and B until the end of the study. The randomization plan was generated using the website, Randomization.com (www.randomization.com).

The age range was 52-83 years with an average of 71 years old. The male/female ratio was 11/27. All of the 38 subjects except for three (non-study eye excluded for history of "wet AMD") had both eyes qualify for the study (73 eyes). Seven eyes of four participants in the A group were pseudophakic; twelve eyes of seven participants in the B group were pseudophakic. As per inclusion/exclusion criteria, cataract surgery could not have been performed within 4 months of the initiation of the study and participants could not have surgery during the term of the study. The study adhered to the tenets of the Declaration of Helsinki; the study was approved by an Integreview Institutional Review Board; Austin, Texas and written informed consents were obtained. Retinal photos and optical coherence tomography images were acquired to document macular drusen.

The primary measured outcome was macular function as tested by micro-perimetry measuring sensitivity of the central 10 degrees of the macula via the MAIA instrument. MAIA is a non-mydriatic, near-infrared, line-scanning, laser ophthalmoscope, which incorporates a high-frequency eye tracker and an automated threshold fundus perimeter. The automated eye tracker locks onto the entire fundus image and captures fixation changes 25 times per second during testing. The fundus image and overlaid testing grid is stored in the instrument allowing exacting follow-up testing. Standard MAIA testing parameters were used for this study: a 61-stimulus grid covering the central 10 degrees of the retina, 4-2 threshold strategy, fixation target red circle 1 degree diameter, stimulus size Goldmann III, background luminance set at $4 \mathrm{asb}$, maximum luminance 1,000 asb, and stimulus dynamic range $36 \mathrm{~dB}$. The radial grid consisted of five rings, 1 degree apart from the center of the fovea to the periphery.

Threshold testing of 61 points was measured at the start of the study, at 6 months, and at 1 year. All subjects had at least one prior testing session to understand the nature of the testing procedure as previous studies have shown a significant increase in sensitivity between the first and second test, but not in subsequent testing. ${ }^{39}$ Measured parameters for each subject were: 1) percent of reduced thresholds of the points tested compared to normal, and 2) average threshold (measured in $\mathrm{dB}$ of light attenuation). Alternative hypothesis testing (1-tailed Student's $t$-test) was used for statistical analysis.

\section{Statistical analysis}

Data in this study were analyzed with SAS statistical software, version 9.4 (Statistical Analysis Software, Cary, NC, USA).

\section{Results}

At the conclusion of the study, the subjects and investigators were unmasked. Subjects taking TA-65 demonstrated improved function by changing from $39.6 \%$ reduced thresholds at the start to $31.7 \%$ reduced thresholds at 6 months. This improvement was maintained with $32.1 \%$ reduced thresholds at the study conclusion. This was compared to the subjects taking the placebo where reduced thresholds were: $41.1 \%$ (start) to $39.5 \%$, then $41.8 \%$ at conclusion $(P=0.04)$ (Figure 1). Moreover, the TA-65 group improved
A

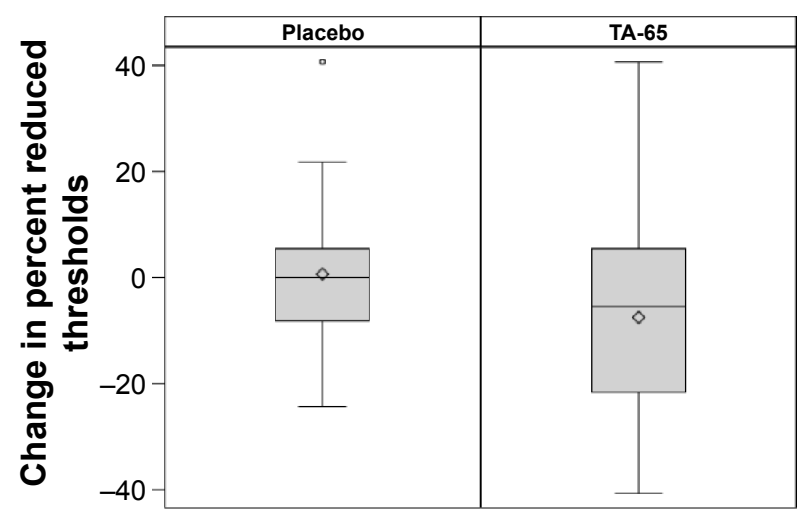

B

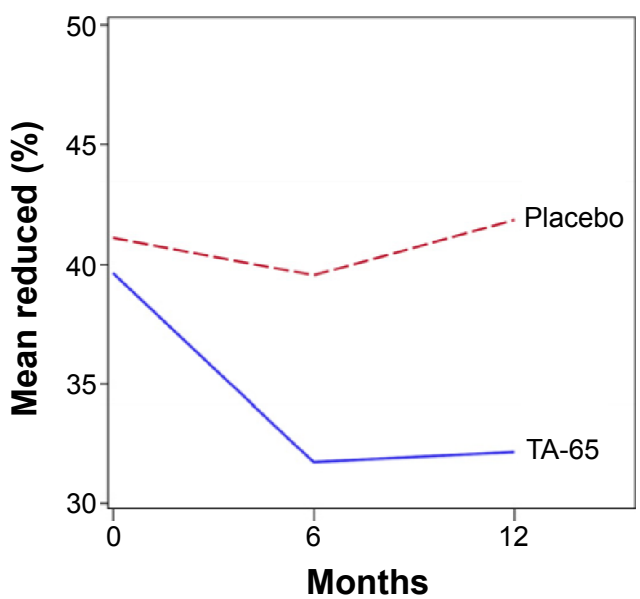

Figure I Change in percent reduced thresholds.

Notes: (A) Box and whisker plot showing change in reduced thresholds for the intervention arm receiving TA-65 compared to placebo. (B) Line graph showing improvement as measured in mean change in reduced thresholds manifest at 6 months and continued at 12 months ( $P$-value 0.04$)$.

Abbreviation: TA, telomerase activator. 
A

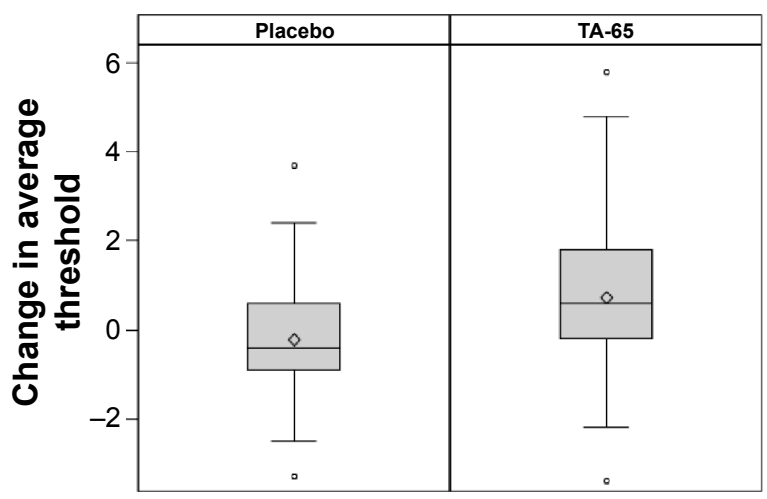

B

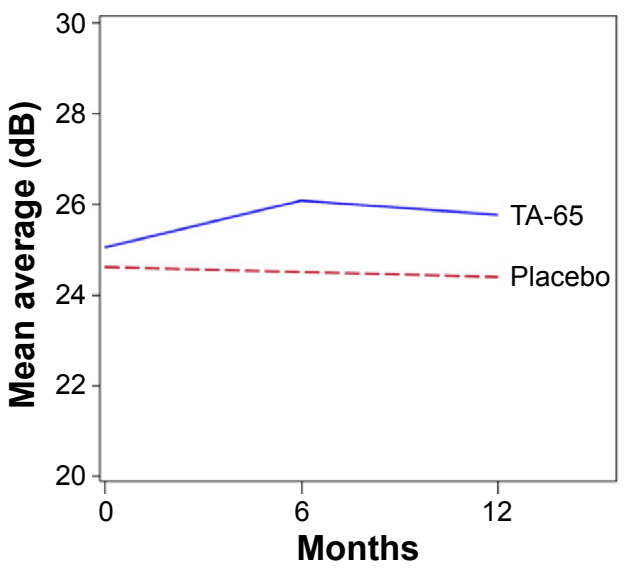

Figure 2 Change in average threshold.

Notes: (A) Box and whisker plot showing change in average threshold for the intervention arm receiving TA-65 compared to placebo. (B) Line graph showing improvement as measured in average threshold (log dB of light attenuation) manifest at 6 months and continued at 12 months ( $P$-value 0.02$)$.

Abbreviation: TA, telomerase activator.

in the measured macular sensitivity where the average $\mathrm{dB}$ (logarithmic attenuation) changed from $25.0 \mathrm{~dB}$ at start to $26.1 \mathrm{~dB}$ at 6 months and 25.76 at 12 months. This was better than the placebo group that had an average $24.6 \mathrm{~dB}$ at start and $24.5 \mathrm{~dB}$ at 6 months and 24.39 at the end. $(P=0.02)$ (Figure 2). Representation of a participant with marked improvement in these parameters is seen in the montage of images in Figure 3. The standard deviations (SDs) for the two parameters were: SD for change in reduced thresholds $=20.870 \%$. SD for change in average threshold $=3.9305 \mathrm{~dB}$.

One adverse reaction was reported to the institutional review board. A study subject had severe loss of vision in one eye from acute optic neuritis due to temporal arteritis (biopsy proven). Although this eye was not part of the study as she had previous treatment for wet macular degeneration in that eye, it was reported as an adverse reaction. She elected to continue in the study. At the unmasking, it was determined that she was in the placebo group. There were no untoward reactions in the TA treated group. Standard visual acuity did not change significantly in either group.

\section{Discussion}

The discovery and elucidation of telomere and telomerase biology warranted the 2009 Nobel Prize in medicine. ${ }^{40}$ Understanding the basic biological mechanisms and emerging impact of telomerase and telomere biology in medicine provides a unique opportunity to study agerelated disease. There are several recognized disease states related to short telomere length: ataxia-telangiectasia, Bloom syndrome, dyskeratosis congenita, Fanconi anemia, Nijmegen breakage syndrome, Werner syndrome, ${ }^{41}$ and idiopathic pulmonary fibrosis. ${ }^{42}$ Short telomere length is also associated with more common age-related diseases: coronary artery disease, ${ }^{21}$ chronic obstructive pulmonary disease, ${ }^{20}$ osteoporosis, ${ }^{43}$ and Alzheimer's disease.${ }^{44,45}$ AMD has recently been added to this list. ${ }^{19}$

Micro-perimetry testing demonstrates functional macular changes not reflected in visual acuity. ${ }^{46}$ It has been validated in AMD, including early AMD, ${ }^{39}$ and was integral in our study of early AMD.

There is currently no treatment that can improve the macula in dry AMD. ${ }^{47}$ Supported by cell culture studies, ${ }^{48}$ telomerase activation has been proposed as a treatment for dry AMD..$^{30,31}$ This study is the first randomly assigned, double blind, placebo-controlled study testing the effect of a TA on macular degeneration.

Similar to other somatic cells, RPE cells undergo telomere shortening due to repeated cell division and the replicative capacity has been shown to decline as a function of donor age. ${ }^{49}$ As RPE cells lack the telomerase enzyme, the cells progress to replicative and oxidative stress induced senescence. Ectopic expression of telomerase in RPE cells increases the replicative capacity and bypasses senescence by preventing telomere shortening. ${ }^{32}$ Markers of senescence are not detected in telomerase positive RPE cells unlike telomerase negative cells. Moreover, telomerase expressing RPE cells retain early-passage phenotype characteristics with regard to protein expression, cell cycle distribution, and capacity for melanization. ${ }^{50}$

TA-65, taken orally, significantly improved the macular function of the treatment subjects compared to controls. Supported by cell biology studies of the RPE, ${ }^{50}$ 

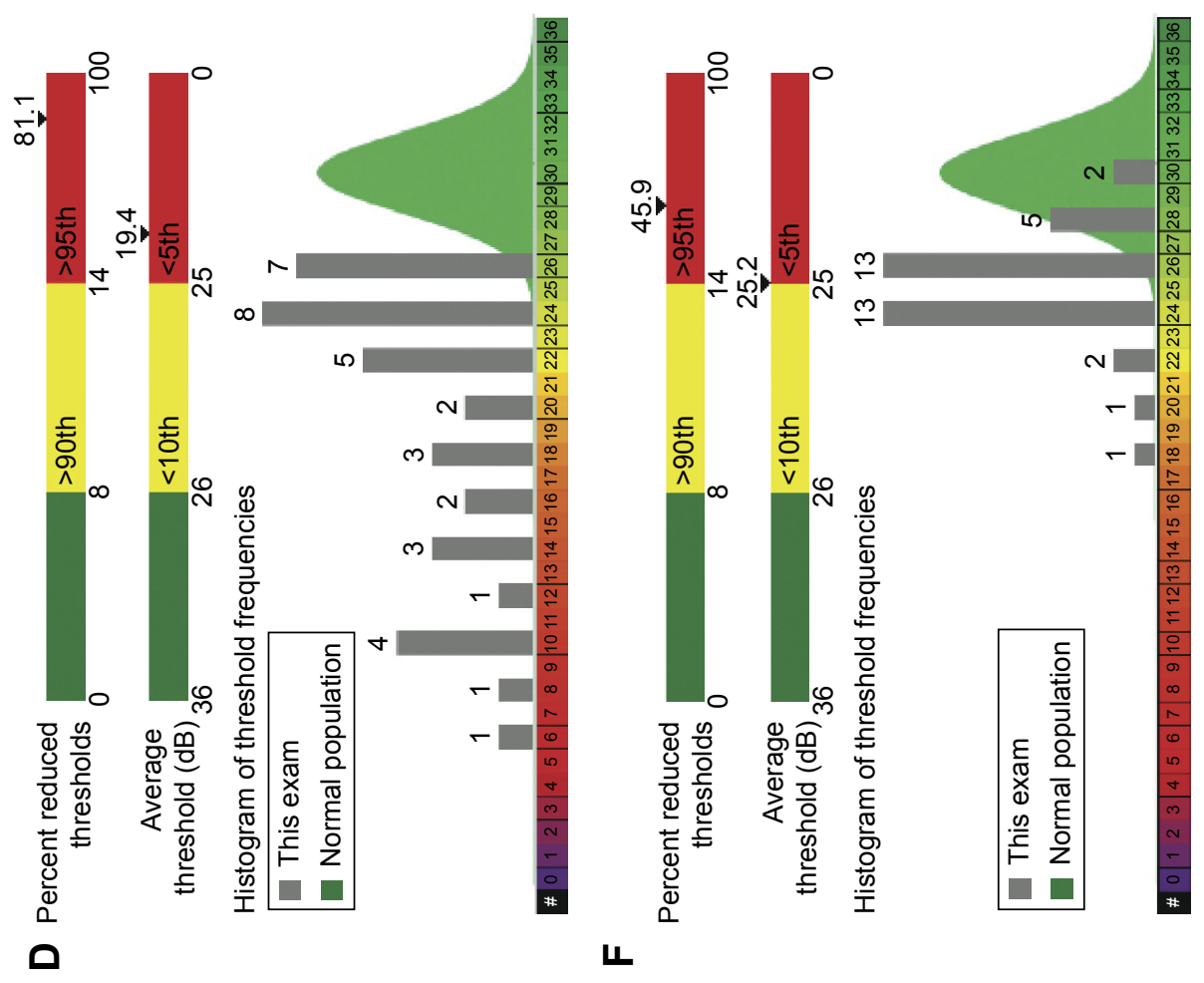

ᄂ
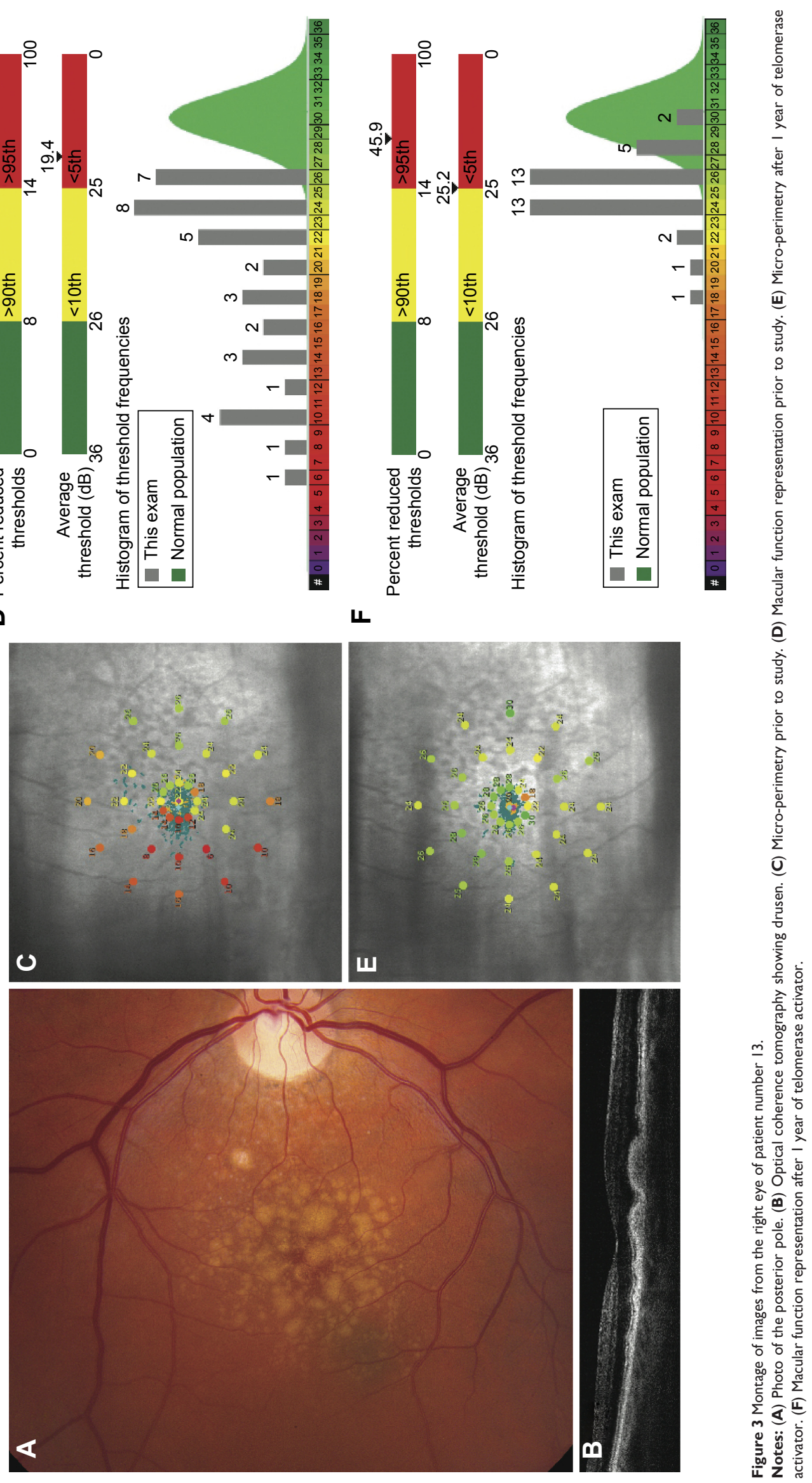
we propose that the treatment effect seen in this study is due to improved function of the RPE due to reduced telomere attrition via telomerase activation. The incidence and prevalence of AMD is expected to rise due to longer life expectancy producing an even greater socioeconomic impact of this disease in the future. ${ }^{51}$ The positive results from this study using an oral TA may stimulate a larger study that, if confirmatory, will present a therapeutic opportunity for telomerase activation and fill an unmet need for those with early AMD.

\section{Acknowledgments}

This study was funded by TA-Sciences, New York. The study is dedicated to mentor and friend Dr Guillermo deVenecia. Dr Peter Flom, a statistics reviewer for PLoS Medicine, reviewed the statistical representation of the study. Dr Anitha Suram, a former postdoc from a telomere lab, and Dr Gunasekaran Singaravelu offered critical review of the manuscript.

\section{Disclosure}

CB Harley is the lead investigator of a use patent on TA-65, was a paid scientific consultant to TA-Sciences, and owns stock in two companies related to this publication (Geron Corporation, and Telomere Diagnostics Inc). The authors report no other conflicts of interest in this work.

\section{References}

1. Friedman DS, O'Colmain BJ, Munoz B, et al. Prevalence of agerelated macular degeneration in the United States. Arch Ophthalmol. 2004;122(4):564-572.

2. Smith W, Assink J, Klein R, et al. Risk factors for age-related macular degeneration: Pooled findings from three continents. Ophthalmology. 2001;108(4):697-704.

3. Ferris FL 3rd, Wilkinson CP, Bird A, et al. Clinical classification of age-related macular degeneration. Ophthalmology. 2013;120(4): 844-851.

4. Jager RD, Mieler WF, Miller JW. Age-related macular degeneration. $N$ Engl J Med. 2008;358(24):2606-2617.

5. Age-Related Eye Disease Study Research G. A randomized, placebocontrolled, clinical trial of high-dose supplementation with vitamins $\mathrm{C}$ and $\mathrm{E}$, beta carotene, and zinc for age-related macular degeneration and vision loss: AREDS report no 8. Arch Ophthalmol. 2001;119(10):1417-1436.

6. Age-Related Eye Disease Study 2 Research G. Lutein + zeaxanthin and omega-3 fatty acids for age-related macular degeneration: the AgeRelated Eye Disease Study 2 (AREDS2) randomized clinical trial. JAMA. 2013;309(19):2005-2015.

7. Besharse JC, Pfenninger KH. Membrane assembly in retinal photoreceptors I. Freeze-fracture analysis of cytoplasmic vesicles in relationship to disc assembly. J Cell Biol. 1980;87(2 Pt 1):451-463.

8. Thumann G, Bartz-Schmidt KU, Kociok N, Heimann K, Schraemeyer U. Ultimate fate of rod outer segments in the retinal pigment epithelium. Pigment Cell Res. 1999;12(5):311-315.

9. Zhao L, Wang Z, Liu Y, et al. Translocation of the retinal pigment epithelium and formation of sub-retinal pigment epithelium deposit induced by sub-retinal deposit. Mol Vis. 2007;13:873-880.
10. Kinnunen K, Petrovski G, Moe MC, Berta A, Kaarniranta K. Molecular mechanisms of retinal pigment epithelium damage and development of age-related macular degeneration. Acta Ophthalmol. 2012; 90(4):299-309.

11. Shelton DN, Chang E, Whittier PS, Choi D, Funk WD. Microarray analysis of replicative senescence. Curr Biol. 1999;9(17):939-945.

12. Matsunaga H, Handa JT, Aotaki-Keen A, Sherwood SW, West MD, Hjelmeland LM. Beta-galactosidase histochemistry and telomere loss in senescent retinal pigment epithelial cells. Invest Ophthalmol Vis Sci. 1999;40(1):197-202.

13. Mishima K, Handa JT, Aotaki-Keen A, Lutty GA, Morse LS, Hjelmeland LM. Senescence-associated beta-galactosidase histochemistry for the primate eye. Invest Ophthalmol Vis Sci. 1999;40(7): 1590-1593.

14. Kurz DJ, Decary S, Hong Y, Erusalimsky JD. Senescence-associated (beta)-galactosidase reflects an increase in lysosomal mass during replicative ageing of human endothelial cells. J Cell Sci. 2000;113(Pt 20): 3613-3622.

15. Armanios M. Telomeres and age-related disease: how telomere biology informs clinical paradigms. J Clin Invest. 2013;123(3):996-1002.

16. Rodier F, Campisi J. Four faces of cellular senescence. J Cell Biol. 2011; 192(4):547-556.

17. Levy MZ, Allsopp RC, Futcher AB, Greider CW, Harley CB. Telomere end-replication problem and cell aging. J Mol Biol. 1992;225(4): 951-960.

18. Harley CB, Futcher AB, Greider CW. Telomeres shorten during ageing of human fibroblasts. Nature. 1990;345(6274):458-460.

19. Weng X, Zhang H, Kan M, et al. Leukocyte telomere length is associated with advanced age-related macular degeneration in the Han Chinese population. Exp Gerontol. 2015;69:36-40.

20. Adnot S, Amsellem V, Boyer L, et al. Telomere Dysfunction and Cell Senescence in Chronic Lung Diseases: Therapeutic Potential. Pharmacol Ther. 2015;153:125-134.

21. Nilsson PM, Tufvesson H, Leosdottir M, Melander O. Telomeres and cardiovascular disease risk: an update 2013. Transl Res. 2013;162(6): 371-380.

22. Weng NP, Levine BL, June CH, Hodes RJ. Regulated expression of telomerase activity in human $\mathrm{T}$ lymphocyte development and activation. J Exp Med. 1996;183(6):2471-2479.

23. Zhu H, Belcher M, van der Harst $P$. Healthy aging and disease: role for telomere biology? Clin Sci (Lond). 2011;120(10):427-440.

24. von Zglinicki T, Saretzki G, Docke W, Lotze C. Mild hyperoxia shortens telomeres and inhibits proliferation of fibroblasts: a model for senescence? Exp Cell Res. 1995;220(1):186-193.

25. Ren JL, Pan JS, Lu YP, Sun P, Han J. Inflammatory signaling and cellular senescence. Cell Signal. 2009;21(3):378-383.

26. Beatty S, Koh H, Phil M, Henson D, Boulton M. The role of oxidative stress in the pathogenesis of age-related macular degeneration. Surv Ophthalmol. 2000;45(2):115-134.

27. Arjamaa O, Nikinmaa M, Salminen A, Kaarniranta K. Regulatory role of HIF-1alpha in the pathogenesis of age-related macular degeneration (AMD). Ageing Res Rev. 2009;8(4):349-358.

28. Harley CB, Liu W, Flom PL, Raffaele JM. A natural product telomerase activator as part of a health maintenance program: metabolic and cardiovascular response. Rejuvenation Res. 2013;16(5):386-395.

29. Fauce SR, Jamieson BD, Chin AC, et al. Telomerase-based pharmacologic enhancement of antiviral function of human CD8+ T lymphocytes. J Immunol. 2008;181(10):7400-7406.

30. Rowe-Rendleman C, Glickman RD. Possible therapy for age-related macular degeneration using human telomerase. Brain Res Bull. 2004; 62(6):549-553.

31. Rastmanesh R. Potential of melatonin to treat or prevent age-related macular degeneration through stimulation of telomerase activity. Med Hypotheses. 2011;76(1):79-85.

32. Bodnar AG, Ouellette M, Frolkis M, et al. Extension of life-span by introduction of telomerase into normal human cells. Science. 1998;279(5349):349-352. 
33. Morales CP, Holt SE, Ouellette M, et al. Absence of cancer-associated changes in human fibroblasts immortalized with telomerase. Nat Genet. 1999;21(1):115-118.

34. Szabo NJ. Dietary safety of cycloastragenol from Astragalus spp.: subchronic toxicity and genotoxicity studies. Food Chem Toxicol. 2014;64:322-334.

35. Midena E, Segato T, Blarzino MC, Degli Angeli C. Macular drusen and the sensitivity of the central visual field. Doc Ophthalmol. 1994; 88(2):179-185.

36. Eisner A, Stoumbos VD, Klein ML, Fleming SA. Relations between fundus appearance and function. Eyes whose fellow eye has exudative age-related macular degeneration. Invest Ophthalmol Vis Sci. 1991; 32(1):8-20.

37. Midena E, Vujosevic S, Convento E, Manfre A, Cavarzeran F, Pilotto E. Microperimetry and fundus autofluorescence in patients with early age-related macular degeneration. Br J Ophthalmol. 2007;91(11): 1499-1503.

38. Neelam K, Nolan J, Chakravarthy U, Beatty S. Psychophysical function in age-related maculopathy. Surv Ophthalmol. 2009;54(2):167-210.

39. Wu Z, Ayton LN, Guymer RH, Luu CD. Intrasession test-retest variability of microperimetry in age-related macular degeneration. Invest Ophthalmol Vis Sci. 2013;54(12):7378-7385.

40. Blackburn EH. Telomeres and telomerase: the means to the end (Nobel lecture). Angew Chem Int Ed Engl. 2010;49(41):7405-7421.

41. Kong CM, Lee XW, Wang X. Telomere shortening in human diseases. FEBS J. 2013;280(14):3180-3193.

42. Armanios MY, Chen JJ, Cogan JD, et al. Telomerase mutations in families with idiopathic pulmonary fibrosis. $N$ Engl J Med. 2007;356(13): 1317-1326.
43. Valdes AM, Richards JB, Gardner JP, et al. Telomere length in leukocytes correlates with bone mineral density and is shorter in women with osteoporosis. Osteoporos Int. 2007;18(9):1203-1210.

44. Deleidi M, Jaggle M, Rubino G. Immune aging, dysmetabolism, and inflammation in neurological diseases. Front Neurosci. 2015;9:172.

45. Boccardi V, Pelini L, Ercolani S, Ruggiero C, Mecocci P. From cellular senescence to Alzheimer's disease: The role of telomere shortening Ageing Res Rev. 2015;22:1-8.

46. Tomkins-Netzer O, Ismetova F, Bar A, Seguin-Greenstein S, Kramer M, Lightman S. Functional outcome of macular edema in different retinal disorders. Prog Retin Eye Res. 2015;48:119-136.

47. Yong JJ, Scott IU, Greenberg PB. Ocular nutritional supplements: are their ingredients and manufacturers' claims evidence-based? Ophthalmology. 2015;122(3):595-599.

48. Park JK, Kim BH, Han YS, Park IK. The effect of telomerase expression on the escape from M2 crisis in virus-transformed human retinal pigment epithelial cells. Exp Mol Med. 2002;34(2):107-113.

49. Tassin J, Malaise E, Courtois Y. Human lens cells have an in vitro proliferative capacity inversely proportional to the donor age. Exp Cell Res. 1979;123(2):388-392.

50. Rambhatla L, Chiu CP, Glickman RD, Rowe-Rendleman C. In vitro differentiation capacity of telomerase immortalized human RPE cells Invest Ophthalmol Vis Sci. 2002;43(5):1622-1623.

51. Owen CG, Fletcher AE, Donoghue M, Rudnicka AR. How big is the burden of visual loss caused by age related macular degeneration in the United Kingdom? Br J Ophthalmol. 2003;87(3):312-317.
Clinical Ophthalmology

\section{Publish your work in this journal}

Clinical Ophthalmology is an international, peer-reviewed journa covering all subspecialties within ophthalmology. Key topics include: Optometry; Visual science; Pharmacology and drug therapy in eye diseases; Basic Sciences; Primary and Secondary eye care; Patient Safety and Quality of Care Improvements. This journal is indexed on

Submit your manuscript here: http://www.dovepress.com/clinical-ophthalmology-journal

\section{Dovepress}

PubMed Central and CAS, and is the official journal of The Society of Clinical Ophthalmology (SCO). The manuscript management system is completely online and includes a very quick and fair peer-review system, which is all easy to use. Visit http://www.dovepress.com/ testimonials.php to read real quotes from published authors. 